Report

\title{
The diabetes prevention and control programme of the Islamic Republic of Iran
}

\author{
F. Azizi, ${ }^{1}$ M.M. Gouya, ${ }^{2}$ P. Vazirian, ${ }^{2}$ P. Dolatshahi ${ }^{2}$ and S. Habibian ${ }^{1}$
}

\begin{abstract}
SUMMARY Diabetes mellitus has become a monumental problem and a major health concern throughout the world. We report on the programme developed by the Islamic Republic of Iran for control and management of diabetes, which involves screening for type 2 diabetes in adults at risk and a systematic approach for delivery of health care to people with diabetes.
\end{abstract}

\section{Introduction}

There is evidence indicating that diabetes in adults must now be recognized as a significant threat to public health in rapidly developing countries; the World Health Organization has proclaimed it "a silent epidemic"[1].

According to global database reports collected by WHO which assess the number of people with diabetes worldwide for 3 specific points in time, viz. the years 1995, 2000 and 2025 [2], it has been estimated that, between 1995 and 2025, the adult population ( $\geq 20$ years) will increase by $64 \%$. The prevalence of diabetes will increase by $35 \%$ (from $4 \%$ in 1995 to $5.4 \%$ in 2025) and the number of diabetics will increase by $122 \%$, i.e. from 135 million cases in 1995 to 300 million in the year 2025, the majority occurring in developing countries. There will be a $42 \%$ increase, from 51 million to 72 million, in the indus- trialized countries and a $170 \%$ increase, from 84 million to 228 million, in the developing countries. By 2025, it is projected that more than $75 \%$ of people with diabetes will reside in developing countries compared to $62 \%$ in 1995 . Over and above the increase in prevalence, researchers have estimated a loss of 5-10 years in life expectancy in patients over the age of 40 [3].

\section{Background}

In recent years type 2 diabetes has claimed the attention of the health authorities of the Islamic Republic of Iran. Since 1991 activities for the prevention and control of diabetes have been initiated as a pilot study in 3 rural areas, but because of the lack of valid screening tests and well-equipped health centres they were discontinued in 1993. Nonetheless, in 1996, a report covering the diabetes situation was presented to

${ }^{1}$ Endocrine Research Centre, Shaheed Beheshti University of Medical Sciences, Babol, Islamic Republic of Iran.

${ }^{2}$ Department of Disease Control and National Committee for the Control and Management of Diabetes, Ministry of Health and Medical Education, Tehran, Islamic Republic of Iran.

Received: 23/04/02; accepted: 06/01/03

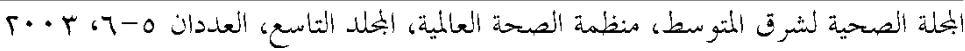


WHO (unpublished report) and a vital step was taken towards diabetes prevention. The same year, the Iranian National Advisory Committee resumed its work, and a new comprehensive national strategy was designed, with the support of the health authorities concerned, for the prevention and control of type 2 diabetes. Meanwhile, provincial advisory subcommittees for diabetes with an endocrinologist or an internist were established as a diabetes focal point. Since 1999, the national programme has been implemented as a pilot project in some areas of 17 provinces of the Islamic Republic of Iran.

\section{The health care system}

The national programme for the prevention and control of diabetes mellitus has been adopted to concur with the current health care system. The Islamic Republic of Iran is committed to achieving health for all through the primary health care approach. Three sectors are currently involved in the provision of health: government services, health insurance, and the private sector. The private health sector plays an important role in the delivery of health care services, especially in urban areas. The public health care system encompasses the district, provincial and national levels.

\section{District level}

From the very outset, the district has been the smallest autonomous unit in the primary health care network. Apart from the sections involved in overall planning, evaluation and supervision, which are located within higher-level facilities, all components of the health care system function at the district level [4]. Despite variations in size and population density, the district is undoubtedly the most appropriate location for problem recognition, identification of objectives specific to the area, coordination of intrasectorial and intersectorial projects, and on-site evaluation and supervision.

\section{The health house}

Health houses are located in villages and are the most outlying rural facility in the network. Each health house is capable of serving about 1500 people, and often covers up to 4 satellite villages in addition to the main village.

Most villages in the Islamic Republic of Iran have far fewer than 1500 inhabitants. The health house is staffed by 1 (or more) male and 1 (or more) female behvarz (community health worker), chosen preferably from among the local inhabitants. The main function of a health house is to offer primary health care services to the community it serves. Candidates used to be required to have completed primary school, however, from 2001, they have had to be high school graduates. Candidates must successfully complete a written exam and be interviewed before enrolment in the training course; their studies span 2 full years. Some of the most important tasks of the behvarz are:

- an annual census of the population covered

- public health education and encouragement of community participation

- family health care services (family planning services, immunization for children $<5$, health care for school age children)

- disease control services (communicable and noncommunicable diseases)

- patient care and referral to the rural health centres when necessary

- environmental health activities

- providing essential drugs

- home visits for follow-up of drop-out cases

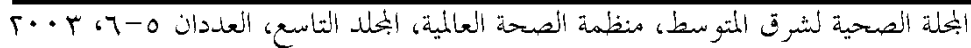


- data collection, documentation, and regular reporting.

Currently, over 22000 behvarz in 14924 health houses give coverage to about 20 million people.

\section{The rural health centre}

The rural health centre is a village-based facility which supervises the health house in its own village and usually 4 other health houses in neighbouring villages. Each rural health centre covers an average of 90000 people. Apart from the general physician, a fully established rural health centre includes on its staff at least 1 person trained in each of the following fields: family health, disease control, environmental health, oral health, laboratory technology, nursing assistance and administration. The physician supervises the staff. The rural health centre's main responsibilities are:

- monitoring supervising, and supporting 3-5 health houses

- providing outpatient care and screening of individuals referred to the health house

- providing oral health services

- performing basic laboratory tests (some)

- providing maternity facilities (some)

- environmental health services

- data collection and regular reporting.

At present, 2243 rural health centres are operational.

\section{National programme for the prevention and control of diabetes mellitus}

\section{History of the programme}

The Islamic Republic of Iran is one of the first countries to have responded to "a call for action" from the Eastern Mediterranean Regional Office of the World Health Organization for the prevention and control of diabetes mellitus [5]

The National Advisory Committee, established in 1992, despite having been inactive for years, finally resumed its operations with new members in 1996. The national programme for the prevention and control of type 2 diabetes was designed in the same year.

The aim of this programme is primary, secondary, and tertiary prevention, through community and high-risk screening, and the integration of diabetes care into the primary healthcare network. The Ministry of Health and Medical Education, with the coordination of the National Diabetes Advisory Committee, launched 6 comprehensive workshops about diabetes for physicians, nurses and nutritionists in 1997 and 1998, in which about 60 physicians, 60 nurses and 60 nutritionists participated each year.

\section{Objectives of the programme}

General objectives

Prevention and control of type 2 diabetes and its complications in the Islamic Republic of Iran.

\section{Specific objectives}

Primary prevention is a specific objective and aims to reduce the prevalence and incidence of type 2 diabetes and also to reduce the prevalence and incidence of modifiable predisposing factors to the condition (obesity, physical inactivity, unhealthy diet, etc).

Strategies for achieving these objectives are to:

- modify life-styles in high-risk Iranian populations

- control and reduce the predisposing factors of diabetes 
- screen those at risk of type 2 diabetes (see screening criteria below)

- control and follow up high risk populations

- enhance the perception and knowledge of the community and health care personnel on diabetes, its predisposing factors and its complications.

Secondary prevention aims to prevent and reduce short-term and long-term complications and to postpone their development-in effect, to alter the natural course of the disease and stop its progression.

Tertiary prevention aims to reduce (and postpone) the number of disabilities and deaths caused by diabetes and its complications.

\section{Outcome}

- Reduce economic costs imposed by diabetes and it complications.

- Reduce disabilities caused by diabetes and its complications.

- Reduce the mortality rate of diabetes and its complications.

- Increase years of effective life.

\section{The programme in operation}

Four levels of health care have been designed (Figure 1). At the first level, the behvarz in the health house, and the kardan (health technician) in the urban health post screen the community, evaluating men and women at risk. At the second level, general physicians and laboratory facilities are made available in rural and urban health centres in a diabetes team. General physicians treat and control all patients according to established protocols (Figure 2). Patients are then referred for early detection of complications (screening) to the third level, which is located in a district hospital where an internist (or endocrinolo- gist if available), a full-time educational nurse and a part-time nutritionist staff the diabetes unit. Patients needing more specific facilities for diagnosis and treatment are then referred to the fourth level, which is situated in a university (provincial) hospital and has an internist (or an endocrinologist if available) and a full-time educational nurse and a part-time nutritionist who constitute the diabetes team in the centre. The third and fourth levels are responsible for detection and management of the complications of diabetes according to set protocols (Figure 3).

\section{Screening criteria for individuals at risk of type 2 diabetes mellitus}

Three groups of individuals have been designated for screening:

- men and women $\geq 30$ years of age who have any of the following:

- history of diabetes mellitus among first-degree relatives (father, mother, brother or sister)

- at least 2 symptoms of diabetes (polyuria, polydipsia, polyphagia)

- blood pressure $\geq 140 / 90 \mathrm{mmHg}$

- obesity (body mass index $\geq 30 \mathrm{~kg} /$ $\mathrm{m}^{2}$ )

- women who have had any of the following:

- $\geq 2$ spontaneous abortions of unknown cause

- intra-uterine fetal death

- children with birth weight $\geq 4 \mathrm{~kg}$

- history of gestational diabetes mellitus

- pregnant women:

- in their 24-28th weeks of pregnancy

- classified as high-risk at the beginning of their pregnancy (includes criteria of groups listed above).

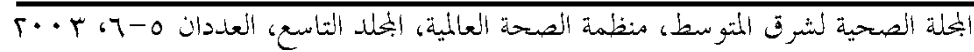




\begin{tabular}{|c|c|c|c|}
\hline & & & $\begin{array}{c}\text { 4th level } \\
\text { Diabetes centre }\end{array}$ \\
\hline & & & $\begin{array}{l}\text { Internist } \\
\text { (endocrinologist), } \\
\text { educational nurse, } \\
\text { nutritionist, consultant } \\
\text { physicians }\end{array}$ \\
\hline & & $\begin{array}{c}\text { 3rd level } \\
\text { Diabetes unit }\end{array}$ & $\begin{array}{l}\text { - Education (public, } \\
\text { patients, health }\end{array}$ \\
\hline & & $\begin{array}{l}\text { Internist (endocrinologist), } \\
\text { educational nurse, } \\
\text { nutritionist, consultant } \\
\text { physicians }\end{array}$ & $\begin{array}{l}\text { personnel) } \\
\text { - Management of } \\
\text { complications } \\
\text { - Feedback }\end{array}$ \\
\hline & $\begin{array}{c}\text { 2nd level } \\
\text { Diabetes team }\end{array}$ & $\begin{array}{l}\text { - Education (public, patients } \\
\text { health personnel) }\end{array}$ & reporting \\
\hline & General physicians & - Early diagnosis of & \\
\hline First level & - Screening those at high risk & & \\
\hline $\begin{array}{l}\text { Behvarz, kardan (with } \\
\text { volunteer aid) }\end{array}$ & $\begin{array}{l}\text { - Early diagnosis of diabetes } \\
\text { - Control and treatment }\end{array}$ & $\begin{array}{l}\text { - Feedback } \\
\text { - Data collection and }\end{array}$ & \\
\hline $\begin{array}{l}\text { - Education of: } \\
\text { - the public } \\
\text { - high risk individuals } \\
\text { - patients } \\
\text { - Follow-up of: } \\
\text { - high risk individuals } \\
\text { - patients } \\
\text { - Data collecting and } \\
\text { reporting }\end{array}$ & $\begin{array}{l}\text { - Referral to the next level } \\
\text { - Patient screening } \\
\text { - Complications } \\
\text { - Quality control } \\
\text { - Feedback } \\
\text { - Education (public, patients) } \\
\text { - Data collection and } \\
\text { reporting }\end{array}$ & $\begin{aligned} \text { reporting } \\
\text { - Research }\end{aligned}$ & \\
\hline Health houses and posts & $\begin{array}{l}\text { Health centres (rural and } \\
\text { urban) }\end{array}$ & District hospital & $\begin{array}{l}\text { University (provincial } \\
\text { hospital) }\end{array}$ \\
\hline
\end{tabular}

Figure 1 Levels of diabetes care provided by the health care system of the Islamic Republic of Iran

\section{Discussion}

The manifestations of diabetes cause considerable human suffering and are increasing burdens on the health care system. The financial costs are enormous. In addition, diabetes causes serious health complications: progressive damage to the eyes, kidneys, nerves and arteries represent the major threats faced. Retinopathy is the

البحلة الصححة لشرق المتو سط، منظمة الصحة العالمية، المخلد الثاسع، العددان ه-7، +.? 


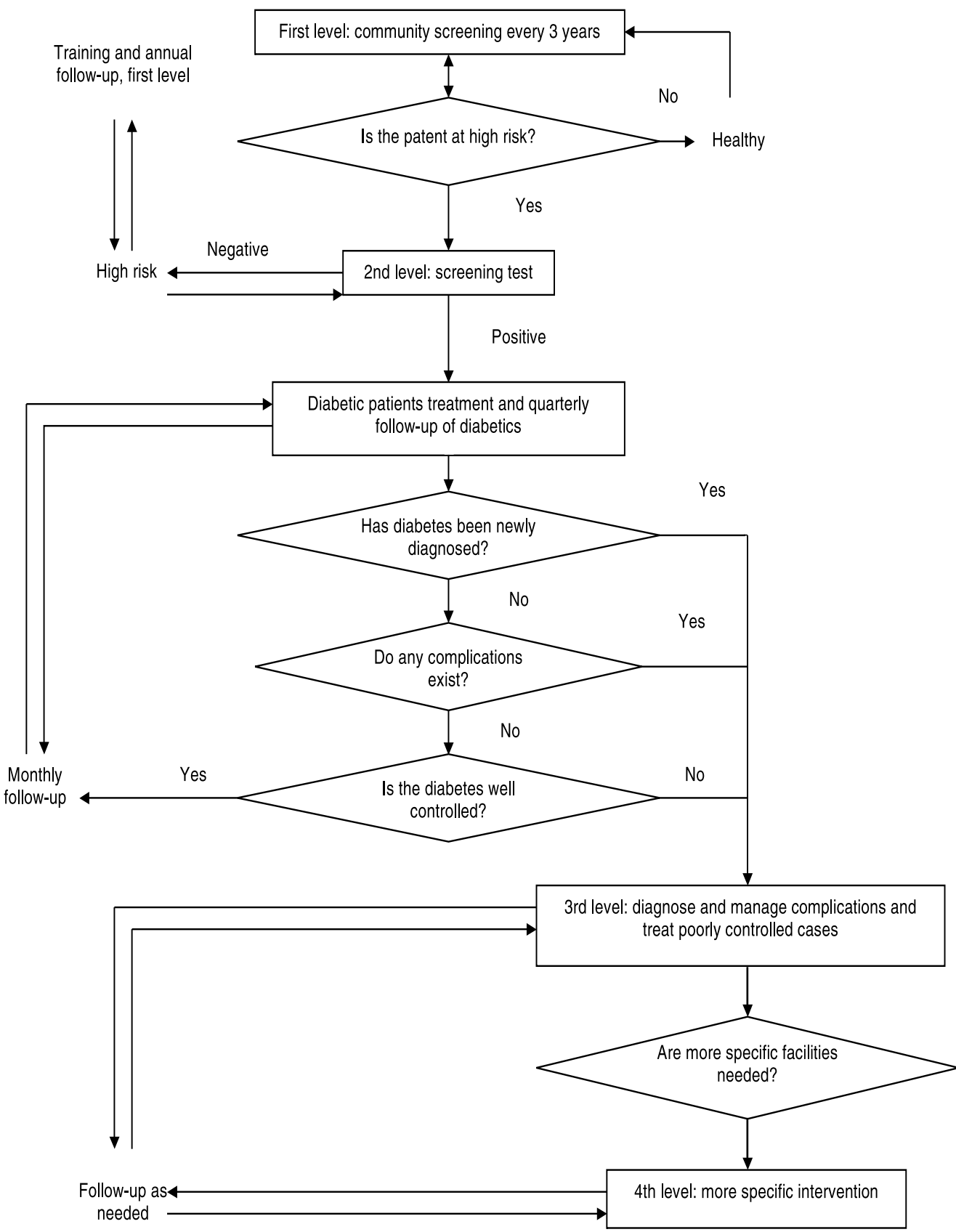

Figure 2 Algorithm for detection and management of diabetes mellitus in the National Diabetes Programme of the Islamic Republic of Iran

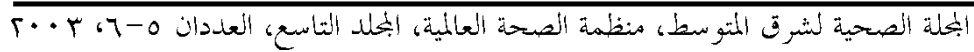




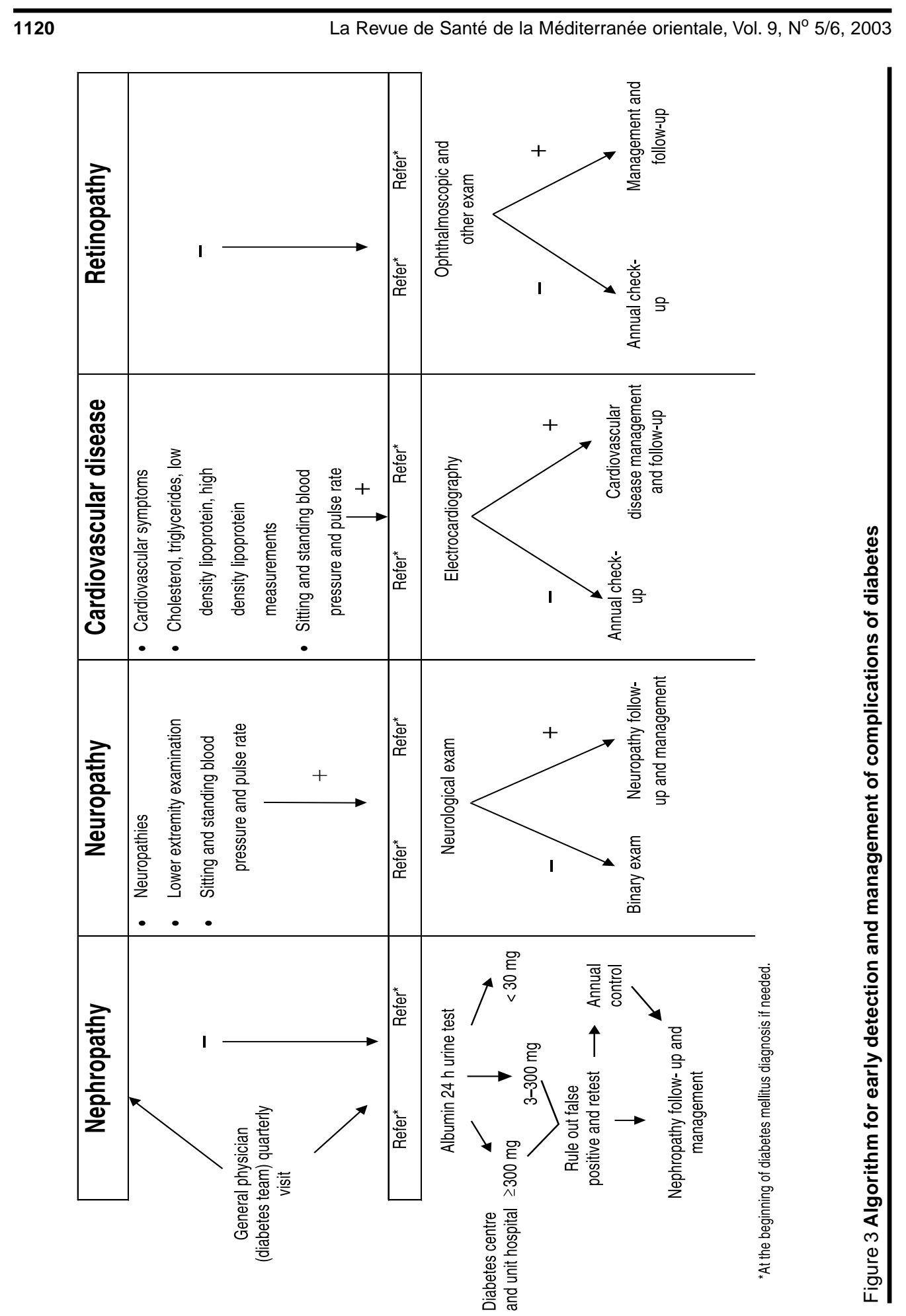

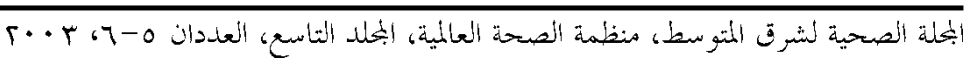


leading cause of visual disability. Progressive impairment of kidney function, culminating in end-stage renal failure, threatens the health and lives of a substantial proportion of those afflicted by diabetes. People with diabetes run a particularly high risk of developing coronary heart disease, a leading cause of death in the diabetic population $[1,2]$.

Despite the considerable repercussions of the problem, evidence indicates that major improvements in quality of life, a reduction in the incidence of complications and a reduction in expenditure can be achieved through effective mechanisms and appropriate actions taken by health authorities [6].

The appropriate control and management of diabetes, education of the population and utilization of advanced technology for diabetes health care would all contribute to a better quality of life. In spite of the high prevalence of diabetes and its complications and the availability of successful prevention strategies, however, essential healthcare requirements and facilities are still lacking for the control of this disease.

Accepting diabetes and its associated complications as a progressive, potentially devastating, disease needing life-long treat- ment and accounting for a significant proportion of health care budgets makes this condition a subject of major concern. Specific considerations for prevention and control of type 2 diabetes are needed at all levels of the healthcare system in order to improve healthcare delivery to patients. Education of healthcare teams in the management of diabetes and methods for increasing knowledge in the community are major aspects that need reinforcement.

The network for control and management of type 2 diabetes in the Islamic Republic of Iran is a systematic approach for delivery of healthcare to patients. Evaluation and monitoring of this network has been initiated, and will play an important role in the enhancement of this urgently needed network.

\section{Acknowledgements}

The authors would like to express their deep appreciation to the members of the National Diabetes Advisory Committee and all persons involved in planning, education and execution of the diabetes control and management programme in various provinces.

\section{References}

1. Diabetes mellitus: Report of a WHO study group. Geneva, World Health Organization, 1985 (WHO Technical Report Series, No. 727).

2. King $\mathrm{H}$, Aubert RE, Herman WH. Global burden of diabetes 1995-2025: prevalence, numerical estimates and projections. Diabetes care, 1998, 21:1414-31.

3. Dobrossy L ed. Prevention in primary care: recommendations for promoting good practice. Copenhagen, WHO Regional Office for Europe, 1995. (EUR/ ICP/CIND 94 01/PB01).
4. Shadpour K. The PHC experience in Iran. Tehran, United Nations Children's Fund, 1994.

5. Diabetes prevention and control. A call for action. Alexandria, Egypt, World Health Organization, Regional Office for the Eastern Mediterranean, 1993.

6. Prevention of diabetes mellitus. Report of a WHO study group. Geneva, World Health Organization, 1994 (WHO Technical Report Series, No. 844).

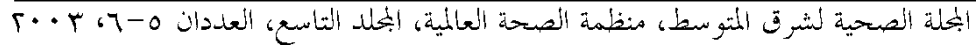

